\title{
Survival of short dental implants in atrophied jaw: a systematic review
}

\author{
Fatimah Assaf ${ }^{1}$, Guilherme Siqueira-lbelli ${ }^{1}$, Rogério Margonar ${ }^{2}$, Pâmela Letícia Santos ${ }^{3^{*}}$, Ana Paula de \\ Souza-Faloni ${ }^{4}$, Thallita Pereira-Queiroz ${ }^{3}$
}

1. MSc in Implantology, Department of Health Sciences, Implantology Post Graduation Course, Dental School, University Center of Araraquara, UNIARA, Araraquara, SP, Brazil.

2. Assistant Professor of Periodontics, Department of Health Sciences, Post-graduation Program in Implantology, University of Araraquara - UNIARA Dental School, SP, Brazil.

3. Assistant Professor of Oral and Maxillofacial Surgery, Department of Health Sciences, Postgraduation Program in Implantology, University of Araraquara - UNIARA Dental School, SP, Brazil. 4. Assistant Professor of Basic Science, Department of Health Sciences, Post-graduation Program in Implantology, University of Araraquara UNIARA Dental School, SP, Brazil..

* Corresponding author: Pâmela Letícia dos Santos I Department of Health Sciences, University of Araraquara (UNIARA) |Rua Carlos Gomes, 1338, Centro, Araraquara-SP / Brasil - CEP 14801-340 | Phone and Fax number: (55)16 30105494 | Email: pamelalsantos@hotmail.com

Trabajo recibido el 17/09/2019.

Aprobado para su publicación el 28/10/2019.

\section{ABSTRACT}

Aim: Short implants are manufactured for use in atrophic regions of the jaw. Therefore, the current does not sufficiently reveal a direct correlation between the impact of implant length on implant survival. The purpose of this systematic review was to compile the evidence of short implant survival in atrophied jaws. Methods: Electronic and manual literature searches were performed by two independent reviewers in several databases, including MEDLINE, EMBASE, and Cochrane Oral Health Group Trials Register, for articles up to September 2015 using the following terms in some combinations: "short implant", "mandible/atrophied jaws", and "implant survival/ survival rate/ survival analysis". Results: The 19 included studies present in average 5.5 years (range 1.0-20.0 years) follow-up and $96.1 \%$ (range $73.4-100.0$ percent) survival rate of the short implants in atrophied mandibular. Conclusions: This systematic review found evidences regarding to safety of short implant placement in atrophied jaws although stronger evidence is essential to confirm this finding.

\section{KEY WORDS}

Short implants; Dental implants, Meta-analysis, Mandible, Atrophied jaws.

Int. J. Inter. Dent Vol. 13(1); 44-46, 2020.

\section{INTRODUCTION}

Implant prostheses has now been widely accepted by both the dentists and patients as an efficacious method to restore partially or completely edentulous patients. However, the placement of dental implants may be limited due to various physical situations, including anatomical limitations such as reduced bone quantity, especially in the posterior mandible. This reduced bone height not only limits the application of implant therapy, but also increases the probability of invasive damage to some anatomical structures, such as the inferior alveolar nerve, maxillary sinus and nasal cavity ${ }^{(1)}$.

Due to this, several techniques to enhance bone quantity have been developed over the years. Among them there are guided bone regeneration (GBR) or sinus floor elevation and augmentation (SFEA). However, even these methods have obtained a level of success, a longterm treatment and financial burden could also discourage patients' motivation $^{(2)}$.

As an alternative, short implants are being increasingly used in extremely resorbed posterior region. According Kim et al. (2015)(3) a short implant should be defined as an implant with a designed intra-bony length of $7 \mathrm{~mm}$ or less.

As advantage short implants placement enables to reduce the sophisticated and expensive surgical procedures required for providing a sufficient osseous to enable implants to be placed. This also prevents the damage of vital anatomical structures (inferior alveolar nerve, maxillary sinus), in addition to shortened treatment time, and reduced cost. However, the limited surface area of short implants can be a potential disadvantage as it has less resistance to occlusal forces ${ }^{(3-4)}$.

Therefore, the current literature is still controversial and the published reviews do not sufficiently reveal a direct correlation between the impact of implant length on implant success/survival because of the discrepancies associated with the dissimilarities among and within the reviewed studies ${ }^{(1)}$. Systematic methods are selected to minimize bias, thus providing more reliable results.

In this way, the aim of this systematic review was answering the question: "Are the short implants provide favorable survival in atrophied jaws? The working hypothesis that short implants provide favorable survival. In this way the purpose of this systematic review was to compile the evidence of short implant survival in atrophied jaws.

\section{MATERIALS AND METHODS}

\section{- Focused Question}

The focused question addressed in this study is: "Are the short implants provide favorable survival in atrophied jaws?

\section{- Eligibility Criteria}

The inclusion criteria were: 1) Evaluation of short implants; 2) Implants placed in atrophic jaw; 3) Provide data on survival rates; 4) Human Clinical Trial; 5) Studies with full text articles; 6) Report a minimum follow up period of 12 months following placement; 7) Articles published in English-language. Original research articles that failed to follow all six criteria described above were excluded from systematic review.

\section{- Search strategy}

Electronic searches of the PubMed, Web of Science and Scopus databases were conducted in September 2015 with a combination of the following words: "short implant", "mandible/atrophied jaws", and "implant survival/ survival rate/ survival analysis". A literature search was conducted using the Endnote Program ${ }^{\mathrm{TM}}$ X7 version (Thomson Reuters, New York, NY, USA), a manager references commercial license that allows the elimination of duplicate references.

Therefore, the assessment of titles and abstracts identified the initial search, which was performed by two investigators (FA and TPQ) independently and checked for agreement. Then, the full text of the articles judged by title and abstract to be relevant were read independently and assessed regarding the selection criteria of inclusion and exclusion. For conflicting evaluations, an agreement was reached following a discussion.

\section{- Data Extraction}

According to described selection criteria, all data were reviewed and 
extracted in duplicated independently (FA and TPQ) and discrepancies were resolved through discussion. The following information was extracted from each study: 1) name of first author; 2) year of publication; 3) implant length; 4) implant diameter; 5) follow-up period; 6) number of mandibular implants placed; 7) survival rate of mandibular implants.

\section{RESULTS}

The PubMed, Web of Science and Scopus search identified 313, 306 , and 354 publications, respectively, resulting in 973 articles. After duplicates were removed 179 records remained. A total of 44 publications were obtained as full-text copies. After the inclusion and exclusion criteria were applied, 19 articles were included (Figure 1).

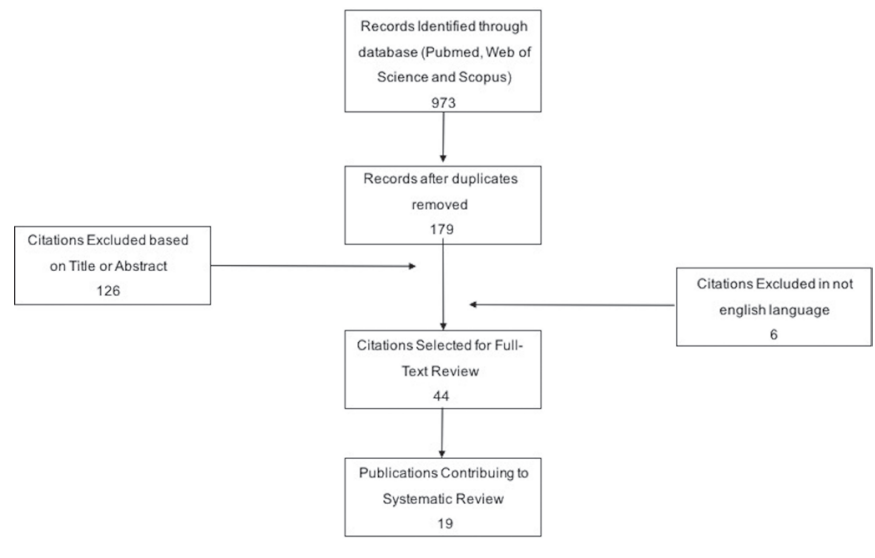

$\overline{\text { Figure 1. Flow-chart showing the literature search and selection process }}$
A descriptive overview of the eligible studies and the data extracted from them are presented in Table 1. The first study was published in 2000, and the latest in 2015. A total of 4,471 short dental implants (lengths from $4.0 \mathrm{~mm}$ to $8.0 \mathrm{~mm}$ ) were reported in the 19 studies that filled the inclusion criteria. The mean follow-up of the publications was 5.5 years (range 1.0-20.0 years). The included studies use cumulative survival rates, providing information on how the risk of implant failure varies over time. The average survival rate of the short implants in atrophied mandibular was $96.1 \%$ (73.4-100.0 percent).

\section{DISCUSSION}

Short implants have become an interesting alternative to bone augmentation in dental implantology. In this way Stellingsma et al. $2014^{(21)}$ evaluated three modes of implant treatment for implant-retained mandibular overdentures in patients with extremely resorbed mandibles. During the evaluation period, significantly more implants were lost in the transmandibular implant and the augmentation groups compared to the group provided with short endosseous implants. In addition, another study ${ }^{(16)}$ compared the outcomes of implants placed in posterior mandibles vertically regenerated with onlay autogenous block bone grafts and short dental implants followed for 12 months after loading. It was observed that implant survival rates were higher more in short dental implants group than in bone grafts group. However, Queiroz et al. 2015(2) detected a survival rate of short implants after 90 days significantly lower than that of regular implants.

Nevertheless, short implants may be considered a reasonable alternative for rehabilitation of severely resorbed mandibles with reduced height due to provide a reduced chair time, expense, and morbidity. Moreover, although implant loss is a frequently used outcome measure for success, the necessity of surgical retreatment seems to be of more relevance for both the patient and the clinician.

Therefore, placing a wide-body implant may be an alternative to avoid

Table 1. Descriptive overview of the data extracted from the reviewed studies on short mandibular implant.

\begin{tabular}{|c|c|c|c|c|c|c|}
\hline Author Year & Implant Length & $\begin{array}{l}\text { Implant } \\
\text { diameter }\end{array}$ & $\begin{array}{l}\text { Follow-up } \\
\text { period (years) }\end{array}$ & $\begin{array}{c}\text { Number of } \\
\text { implants placed }\end{array}$ & $\begin{array}{c}\text { Number of } \\
\text { implants failed }\end{array}$ & $\begin{array}{c}\text { Survival Rate } \\
(\%)\end{array}$ \\
\hline Anitua et al. $2013^{(4)}$ & 5.5 and $6.5 \mathrm{~mm}$ & $3.75-6.0 \mathrm{~mm}$ & 01 & 114 & 02 & 98.2 \\
\hline Anitua et al. $2014^{(5)}$ & 5.5 and $6.5 \mathrm{~mm}$ & $3.75-5.0 \mathrm{~mm}$ & 02 & 45 & 00 & 100.0 \\
\hline Bratu et al. $2014^{(6)}$ & $6.0 \mathrm{~mm}$ & $4.5-6.0 \mathrm{~mm}$ & 02 & 33 & 00 & 100.0 \\
\hline Demiralp et al. $2015^{(7)}$ & $5.0-8.0 \mathrm{~mm}$ & $3.0-5.0 \mathrm{~mm}$ & 02 & 371 & 10 & 97.3 \\
\hline Deporter et al. $2014{ }^{(8)}$ & $5.0-8.0 \mathrm{~mm}$ & $\mathrm{NI}$ & 20 & 53 & 14 & 73.4 \\
\hline Friberg et al. $2000^{(9)}$ & 6.0 and $7.0 \mathrm{~mm}$ & $3.75-5.0 \mathrm{~mm}$ & 14 & 260 & 18 & 92.3 \\
\hline Grant et al. $2009^{(10)}$ & $8.0 \mathrm{~mm}$ & $3.5-6.0 \mathrm{~mm}$ & 02 & 335 & 06 & 98.2 \\
\hline Guljé et al. $2012^{(11)}$ & $6.0 \mathrm{~mm}$ & $4.0 \mathrm{~mm}$ & 01 & 48 & 02 & 96.0 \\
\hline Guljé et al. $2014{ }^{(12)}$ & $6.0 \mathrm{~mm}$ & $4.0 \mathrm{~mm}$ & 01 & 31 & 00 & 100.0 \\
\hline Kim et al. $2015^{(3)}$ & $7.0 \mathrm{~mm}$ & $4.5-6.0 \mathrm{~mm}$ & 01 & 46 & 01 & 97.8 \\
\hline Lops et al. $2012^{(13)}$ & $8.0 \mathrm{~mm}$ & $3.75-4.8 \mathrm{~mm}$ & 20 & 66 & 02 & 96.9 \\
\hline Maló et al. $20111^{(14)}$ & $7.0 \mathrm{~mm}$ & $4.0 \mathrm{~mm}$ & 05 & 196 & 09 & 95.4 \\
\hline Mangano et al. $2014{ }^{(15)}$ & $8.0 \mathrm{~mm}$ & $4.8 \mathrm{~mm}$ & 10 & 91 & 01 & 98.9 \\
\hline Peñarrocha-Oltra et al. $2014{ }^{(16)}$ & $7.0 \mathrm{~mm}$ & $4.2-5.5 \mathrm{~mm}$ & 01 & 35 & 01 & 97.1 \\
\hline Pieri et al. $2012{ }^{(17)}$ & $6.0 \mathrm{~mm}$ & $4.0 \mathrm{~mm}$ & 02 & 61 & 02 & 96.8 \\
\hline Pistilli et al. $2013^{(18)}$ & $6.0 \mathrm{~mm}$ & $4.0 \mathrm{~mm}$ & 01 & 41 & 00 & 100.0 \\
\hline Seemann et al. $2015^{(19)}$ & $5.0 \mathrm{~mm}$ & $4.0 \mathrm{~mm}$ & 02 & 32 & 01 & 97.5 \\
\hline Slotte et al. $2012^{(20)}$ & $4.0 \mathrm{~mm}$ & $4.1 \mathrm{~mm}$ & 02 & 87 & 07 & 92.3 \\
\hline Stellingsma et al. 2014 (21) & $8.0 \mathrm{~mm}$ & $\mathrm{NI}$ & 10 & 80 & 01 & 98.0 \\
\hline
\end{tabular}


grafting procedures in compromised bone height. The purpose of this systematic review was to compile the evidence of short implant survival in atrophied jaw. It is important to note that among the selected studies the implant lengths placed varying from $4.0 \mathrm{~mm}$ to $8.0 \mathrm{~mm}$. Recently, the length definition was changing and short implants are considered being shorter than $8 \mathrm{~mm}$ of functional intraosseous length ${ }^{(10,13,15)}$. However, the definition varied significantly among studies, with some defining short dental implants to be $<7 \mathrm{~mm}$ in length ${ }^{(3)}$.

In our findings, although Slotte et al. 2012(20) showed that $4 \mathrm{~mm}$ implants can support a fixed dental prosthesis in severely resorbed posterior mandibles for at least 2 years, survival rate is slightly lower than in similar studies on 6 to $8.5 \mathrm{~mm}$ implants ${ }^{(12,22)}$. As implant length increases, the surface area available to resist occlusal forces increases proportionately. Therefore, it would seem that shorter-length implants have an inherent disadvantage in terms of integration and long-term success. Nevertheless, other studies ${ }^{(9)}$ including implants higher than $7.0 \mathrm{~mm}$ have shown similar survival rates to that found by Slotte et al. $2012^{(20)}$.

Another possible way to increase the surface area available to resist occlusal forces is adjust the implant diameter range. Finite element studies suggest on implant with a wider diameter is more favorable in reducing the stress distribution in bone surrounding the implants ${ }^{(23)}$. Beyond that a recent study ${ }^{(24)}$ evaluated the success and survival rates, periimplant parameters, and mechanical and prosthetic postloading complications of narrow diameter implants followed over a 10 -year period. They concluded that narrow diameter implants can be used with confidence where a regular diameter implant is not suitable. In our study implant diameters varying from $2.5 \mathrm{~mm}$ to $8.0 \mathrm{~mm}$ in the 19 reports that filled the inclusion criteria. This could be considered a limitation of this study, once the interval range was large. This complicates the short implants survival analysis based only on height of them.

\section{CLINICAL RELEVANCE}

The current literature is still controversial and the published reviews do not sufficiently reveal a direct correlation between the impact of implant length on implant success/survival because of the discrepancies associated with the dissimilarities among and within the reviewed studies. Systematic methods are selected to minimize bias, thus providing more reliable results.

\section{CONFLICT OF INTEREST}

The authors declare that they have no conflicts of interest.

\section{AUTHORS' CONTRIBUTIONS}

Assaf $\mathrm{F}$ and Ibelli GS - Managed the literature searches. Critical revision. Final approval.

Margonar R: Quantitative analysis of results. Critical revision. Final approval.

Santos PL: Data collection and analysis. Manuscript writing. Critical revision. Final approval.

Queiroz TP: Conception and design of the study. Critical revision. Final approval.

\section{References}

1. das Neves FD, Fones D, Bernardes SR, do Prado CJ, Neto AJ. Short implants--an analysis of longitudinal studies. Int J Oral Maxillofac Implants. 2006; 21(1): 86-93. 2. Queiroz TP, Aguiar SC, Margonar R, de Souza Faloni AP, Gruber R, Luvizuto ER. Clinical study on survival rate of short implants placed in the posterior mandibular region: resonance frequency analysis. Clin Oral Implants Res. 2015;26(9):1036-42. 3. Kim Y-K, Yun P-Y, Yi Y-J, Bae J-H, Kim S-B, Ahn G-J. One-year prospective study of 7-mm-long implants in the mandible: installation technique and crown/implant ratio of 1.5 or less. J Oral Implantol. 2015;41(2):E30-E5.

4. Anitua E, Piñas L, Orive G. Retrospective study of short and extra-short implants placed in posterior regions: influence of crown-to-implant ratio on marginal bone loss. Clin Implant Dent Relat Res. 2015;17(1):102-10.

5. Anitua E, Alkhraist MH, Piñas L, Begoña L, Orive G. Implant survival and crestal bone loss around extra-short implants supporting a fixed denture: the effect of crown height space, crown-to-implant ratio, and offset placement of the prosthesis. Int Oral Maxillofac Implants. 2014;29(3):682-9

6. Bratu E, Chan H-L, Mihali S, Karancsi O, Bratu DC, Fu J-H, et al. Implant surviva rate and marginal bone loss of 6-mm short implants: a 2-year clinical report. Int J Oral Maxillofac Implants. 2014;29(6):1425-8.

7. Demiralp KO, Akbulut N, Kursun S, Argun D, Bagis N, Orhan K. Survival rate of short, locking taper implants with a plateau design: a 5-year retrospective study. Biomed Res Int. 2015;2015:197451.

8. Deporter D, Pharoah M, Yeh S, Todescan R, Atenafu EG. Performance of titanium alloy sintered porous-surfaced (SPS) implants supporting mandibular overdentures during a 20-year prospective study. Clin Oral Implants Res. 2014; 25(2):e189-95.

9. Friberg B, Gröndahl K, Lekholm U, Brånemark PI. Long-term follow-up of severely atrophic edentulous mandibles reconstructed with short Brånemark implants. Clin Implant Dent Relat Res. 2000;2(4):184-9.

10. Grant BTN, Pancko FX, Kraut RA. Outcomes of placing short dental implants in the posterior mandible: a retrospective study of 124 cases. J Oral Maxillofac Surg. 2009;67(4):713-7.

11. Guljé F, Raghoebar GM, Ter Meulen JWP, Vissink A, Meijer HJA. Mandibular overdentures supported by 6-mm dental implants: a 1-year prospective cohort study. Clin Implant Dent Relat Res. 2012;14:e59-e66.

12. Gulje FL, Raghoebar GM, Vissink A, Meijer HJ. Single restorations in the resorbed posterior mandible supported by 6-mm implants: a 1-year prospective case series study. Clin Implant Dent Relat Res. 2015;17(Suppl 2):e465-71.

13. Lops D, Bressan E, Pisoni G, Cea N, Corazza B, Romeo E. Short implants in partially edentulous maxillae and mandibles: A 10 to 20 years retrospective evaluation. Int J Dent. 2012;2012:351793.
14. Malo $P$, de Araujo M, Lopes A. Short implants in posterior jaws. A prospective 1-year study. Eur J Oral Implantol. 2011;4(1):47-53.

15. Mangano FG, Shibli JA, Sammons RL, laculli F, Piattelli A, Mangano C. Short (8-mm) locking-taper implants supporting single crowns in posterior region: a prospective clinical study with 1-to 10-years of follow-up. Clin Oral Implants Res. 2014;25(8):933-40.

16. Peñarrocha-Oltra D, Aloy-Prósper A, Cervera-Ballester J, Peñarrocha-Diago M Canullo L, Peñarrocha-Diago M. Implant treatment in atrophic posterior mandibles: vertical regeneration with block bone grafts versus implants with $5.5-\mathrm{mm}$ intrabony length. Int J Oral Maxillofac Implants. 2014;29(3): 659-66.

17. Pieri F, Aldini NN, Fini M, Marchetti C, Corinaldesi G. Preliminary 2-year report on treatment outcomes for 6 -mm-long implants in posterior atrophic mandibles. Int $\mathrm{J}$ Prosthodont. 2012;25(3):279-89.

18. Pistilli R, Felice P, Cannizzaro G, Piatelli M, Corvino V Barausse $C$, et al. Posterior atrophic jaws rehabilitated with prostheses supported by $6 \mathrm{~mm}$ long 4 $\mathrm{mm}$ wide implants or by longer implants in augmented bone. One-year post-loading results from a pilot randomised controlled trial. Eur J Oral Implantol. 2013;6(4):35972.

19. Seemann R, Marincola M, Seay D, Perisanidis C, Barger N, Ewers R. Preliminary results of fixed, fiber-reinforced resin bridges on four 4- $\times 5-\mathrm{mm}$ ultrashort implants in compromised bony sites: A pilot study. J Oral Maxillofac Surg. 2015; 73(4):630-40.

20. Slotte C, Grønningsaeter A, Halmøy AM, Öhrnell LO, Stroh G, Isaksson S, et al. Four-millimeter implants supporting fixed partial dental prostheses in the severely resorbed posterior mandible: two-year results. Clin Implant Dent Relat Res. 2012:14:e46-e58.

21. Stellingsma K, Raghoebar GM, Visser A, Vissink A, Meijer HJA. The extremely resorbed mandible, 10-year results of a randomized controlled trial on 3 treatment strategies. Clin Oral Implants Res. 2014;25(8):926-32.

22. Taschieri S, Corbella S, Molinari R, Saita M, Del Fabbro M. Short implants in maxillary and mandibular rehabilitations: interim results (6 to 42 months) of a prospective study. J Oral Implantol. 2015;41(1):50-5

23. Mohammed Ibrahim M, Thulasingam C, Nasser KS, Balaji V, Rajakumar M Rupkumar P. Evaluation of design parameters of dental implant shape, diameter and length on stress distribution: a finite element analysis. J Indian Prosthodont Soc. 2011:11(3):165-71.

24. Arisan V, Bolukbasi N, Ersanli S, Ozdemir T. Evaluation of 316 narrow diameter implants followed for 5-10 years: a clinical and radiographic retrospective study. Clin Oral Implants Res. 2010;21(3):296-307. 